\title{
La qāfiya nel Kaššāf ișțilāhāāt al-funūn. Venezia, Cafoscarina, 2007, 101 p. [index des entrées]. (Eurasiatica, 77)
}

Justine Landau

\section{(2) OpenEdition}

Journals

Édition électronique

URL : http://journals.openedition.org/abstractairanica/38003

DOI : 10.4000/abstractairanica.38003

ISSN : 1961-960X

Éditeur :

CNRS (UMR 7528 Mondes iraniens et indiens), Éditions de l'IFRI

\section{Édition imprimée}

Date de publication : 8 avril 2010

ISSN : 0240-8910

Référence électronique

Justine Landau, « La qāfiya nel Kaššāf iștilāhāāt al-funūn. Venezia, Cafoscarina, 2007, 101 p. [index des entrées]. (Eurasiatica, 77) », Abstracta Iranica [En ligne], Volume 30 | 2010, document 256, mis en ligne le 08 avril 2010, consulté le 26 septembre 2020. URL : http://journals.openedition.org/ abstractairanica/38003 ; DOI : https://doi.org/10.4000/abstractairanica.38003

Ce document a été généré automatiquement le 26 septembre 2020

Tous droits réservés 


\title{
La qāfiya nel Kaššāf ișțilāhāat al- funūn. Venezia, Cafoscarina, 2007, 101 p. [index des entrées]. (Eurasiatica, 77)
}

\author{
Justine Landau
}

1 Version publiée de la thèse de laurea de l'A., cet ouvrage se rattache au projet d'étude des sources de la théorie arabo-persane de la rime ( $q a \bar{a} f i y e)$ conduit par Riccardo Zipoli en collaboration avec Stefano Pellò, et déjà riche de plusieurs publications centrées sur la réception de la théorie « hétérodoxe » de Nașīr al-Dīn Țūsī. Mais en se penchant sur le Kaššăf iștilāhāat al-funūn, dictionnaire des termes techniques composé en Inde en 1158/1745 par le savant musulman Muhammad A‘lā ibn 'Alī al-Tahānawī, l'A. aborde délibérément la problématique par ses marges. Loin d'être consacré à la métrique ou aux rimes en particulier, le Kaššăf englobe le lexique de tous les savoirs indistinctement, depuis les sciences religieuses et les sciences naturelles jusqu'à la philosophie, la mathématique et même la magie. La visée d'al-Tahānawī était claire : il avait conçu un ouvrage de référence pour familiariser les étudiants avec le plus grand nombre de vocables techniques en usage, répartis en deux sections, arabe et persane, conformément au bilinguisme de son temps. De fait, cet incontournable thesaurus des savoirs de l'Inde moghole a conservé un certain prestige auprès des spécialistes de la culture classique.

2 En isolant les 41 entrées du dictionnaire relatives à la « science des rimes " (éléments constitutifs: hurūêf et harakāt, typologie : alqāb ou ḥudūd, défauts: 'uyūb), qu'elle réordonne thématiquement, traduit et annote, L'A. met en lumière le fonds commun qui pouvait circuler en la matière, et la place dévolue à la discipline dans le système des savoirs du temps. Sa présentation fournit l'occasion de développements éclairants sur le traitement différentiel de l'arabe et du persan dans le corps de l'ouvrage, examiné à l'aune de la tradition lexicographique. Mais l'essentiel de l'analyse est consacré à la 
typologie des sources sur la qāfiye citées dans le Kaššăf. Celles-ci sont appréciées selon leur langue, le genre de textes dont elles relèvent, et l'usage qu'en fait al-Tahānawī.

On regrettera seulement que cette étude utile et rigoureuse s'achève en mode mineur, sur la dépréciation du Kaššăf comme source pour l'histoire de la théorie de la rime. Compilation de manuels et d'abrégés disparates, le Kǎš̌ăf fait certes peu de place aux ouvrages spécialisés, qui ne sont cités, au mieux, que de seconde main, à l'instar de Ṭūsĩ. Les imprécisions relevées dans le détail confirment en outre

qu'al-Tahānawī, qui n'avait rien d'un expert, n'a abordé la science des rimes que par souci d'exhaustivité. L'ouvrage n'en a pas moins contribué à la diffusion de textes mineurs, voire de définitions non canoniques de la qăfiye, et il est à souhaiter que les investigations sur ce texte et sur sa réception se poursuivent, notamment dans le cadre d'autres disciplines.

INDEX

Thèmes : 11.1.1. Littérature persane classique

\section{AUTEURS}

JUSTINE LANDAU

Paris 